\title{
The polymerase chain reaction: current and future clinical applications
}

\author{
Jennifer R Lynch, Jennifer M Brown
}

\begin{abstract}
The polymerase chain reaction has undergone rapid improvement since its initial development, such that the technique currently permits rapid, accurate, predictive tests to be made in the field of prenatal diagnosis and has greatly aided forensic medicine. It is anticipated that the polymerase chain reaction will also facilitate advances in other fields, in particular preimplantation diagnosis, virology, bacteriology, and cancer therapy.
\end{abstract}

The polymerase chain reaction (PCR) permits the specific in vitro production of multiple copies of defined fragments of DNA. The reaction is highly specific and extremely sensitive, enabling one copy of a sequence in a single cell to be detected. ${ }^{1}$ PCR is rapid, a typical 30 cycle amplification reaction taking approximately three hours. Its use has enhanced previously established diagnostics based on DNA, particularly prenatal diagnosis, and now looks set to facilitate great improvements in preimplantation diagnosis, cancer therapy, forensic medicine, and public health. This short review aims to explain how PCR works, to summarise its current use, and to discuss its potential for the future.

The development of the polymerase chain reaction One of the first genetic diseases to be studied at the DNA sequence level was sickle cell anaemia. This was closely followed by the $\beta$ thalassaemia syndromes, which are also the result of mutations affecting the $\beta$

Nuffield Department of Clinical Medicine, John Radcliffe Hospital, Headington, Oxford OX3 9DU. J R Lynch, J M Brown

Correspondence to Dr Lynch.

Received for publication 16 August 1989. Accepted for publication 23 August 1989. globin gene. ${ }^{2}$ To date there are in the region of $\sim 5000$ base pairs (bp) of sequence around the cluster of globin genes on chromosome 11 , one member of which is $\beta$ globin. ${ }^{3}$ The availability of sequence information made the sickle cell mutation the ideal candidate for the first attempts at gene amplification and prenatal diagnosis using PCR. ${ }^{4}$ PCR usually depends on knowing a minimum DNA sequence of 17 bp on either side of the region of DNA to be studied. The complementary oligomers to these small regions are used to prime the amplification of the target sequence and are therefore known as 'primers'.

In the case of sickle cell anaemia, two $20 \mathrm{bp}$ oligonucleotide primers were constructed which were complementary to the $\beta$ globin gene. These primers flanked the region of the sickle cell mutation and hybridised to different strands of the DNA molecule (fig 1). The PCR procedure involved repeated cycles of heat denaturation, annealing, and primer extension. Heat denaturation unravels the DNA so that it becomes single stranded. During annealing the oligonucleotide primers, present in vast molar excess, hybridise specifically to their complementary sequences and, finally, a DNA polymerase extends the primers by incorporating deoxynucleotides to form a new complementary strand of DNA. By repeated cycles of denaturation, annealing, and extension, the new strands themselves act as templates for the DNA primers and the process leads to an exponential amplification of DNA bounded by the primers. The termini of the fragments formed by PCR are defined by the primers, which themselves become incorporated into the fragments. Therefore, by the end of 30 cycles, blunt ended fragments of a specified size are present in excess compared with those with free ends generated in the first rounds of amplification. This basic cycle of denaturation, annealing, and extension in the presence of a DNA polymerase, excess primers, and excess nucleotides is termed the polymerase chain reaction. ${ }^{5}$

The detection of the sickle cell mutation involved hybridisation of the PCR product with a radioactively 


$$
\begin{aligned}
& - \text { Original DNA } \\
& \text { Oligonucieotide primer } \\
& \text { Newly synthesised } \\
& \text { DNA strand }
\end{aligned}
$$

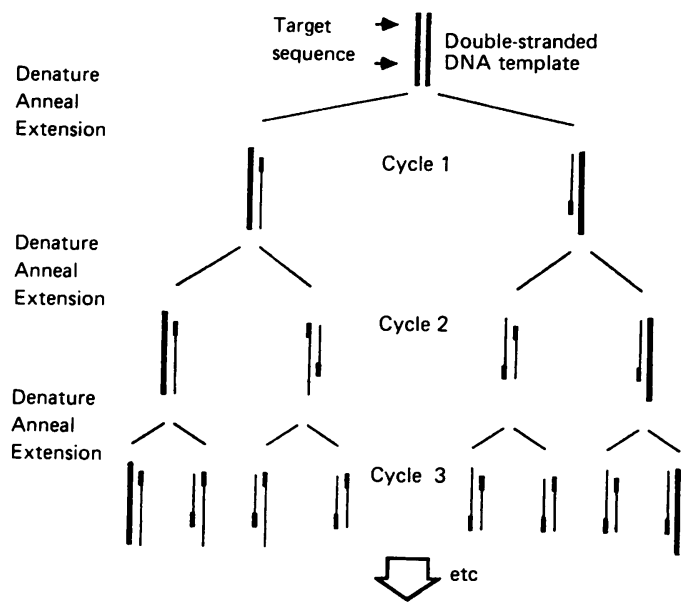

Figure 1 Schematic diagram of the polymerase chain reaction. The original double stranded DNA template is heat denatured to produce single stranded DNA molecules. In the annealing phase specific oligonucleotides hybridise to the target DNA sequence. Then, in the presence of a DNA polymerase and excess deoxynucleotides, the oligonucleotides act as primers for the synthesis of new DNA strands. These subsequently act as templates in the following rounds of the amplification reaction.

labelled oligonucleotide followed by digestion of these new hybrid molecules with the enzyme DdeI. DNA fragments indicative of the presence or absence of this enzyme cutting site, which is known to be destroyed by the sickle cell mutation, were visualised by autoradiography thus permitting the rapid diagnosis of sickle cell disease and sickle cell trait.

Since the first reports, PCR has undergone rapid development. ${ }^{6-9}$ The main improvement has been the isolation and subsequent cloning of the gene for a thermostable DNA polymerase. ${ }^{10} 11$

In early experiments the Klenow fragment of Escherichia coli DNA polymerase I was used. These experiments suffered from two main deficiencies. First, the Klenow fragment was heat labile so that a fresh aliquot of enzyme had to be added after each heat denaturation step. Secondly, the prime annealing temperature had to be kept relatively low and hence resulted in non-specific priming. The low annealing temperature did not present problems if specific radioactively labelled oligonucleotides were used to probe the amplified material. However, this meant that it was virtually impossible to use direct visual- isation methods because the PCR reaction would sometimes produce multiple bands.

The more thermostable Taq DNA polymerase, isolated from the thermophilic bacterium Thermus aquaticus, enabled reactions to proceed without the need for enzyme replenishment. ${ }^{8}$ It also gave an increased yield of DNA fragments and vastly improved specificity owing to increased annealing and extension temperatures. This improvement in specificity meant that direct visualisation of products became possible. ${ }^{1011}$ Perhaps more importantly it also enabled the cycling process to be automated.

Subsequent developments have centred around the use and manipulation of primers. ${ }^{69}$ As previously mentioned, the primers become incorporated into the amplified product and define the termini of the fragments. The addition of short lengths of extra sequence to primers, that is, sequence which is not complementary to the region being amplified, have been shown not to disrupt the amplification process. ${ }^{12}$ Hence, the addition of restriction enzyme recognition sequences immediately adjacent to the primers permits the cloning of the amplified product. ${ }^{12}$ The possibility of direct cloning of DNA from PCR is useful in obtaining and analysing genes with multiple alleles or genes in which a large number of mutations are thought to be present. This procedure has been taken a step further by the use of primers not only for the amplification procedure but also for providing priming sites for sequencing directly from the amplified product, thereby omitting the cloning step altogether. ${ }^{13}$ This latter modification has been used in examining the HLA-DQA locus and serves to illustrate the obvious applications for service laboratories. ${ }^{14}$

It is also possible to use mRNA as the starting material for PCR. ${ }^{15}$ Here cDNA is made using reverse transcriptase and conventional techniques, and the amplification reaction occurs in the usual fashion using the cDNA as the initial template. As a variation on this procedure, transcripts of genes encoding molecules with variable $5^{\prime}$ ends or with unknown upstream or downstream sequences can be made amenable to PCR using only one known primer and an artificial primer comprising an anchor sequence attached to a homopolymer tail. These approaches, using what is called anchor PCR techniques, have been shown to be useful in studying the variable region of $T$ cell receptor $\delta$ chains ${ }^{16}$ and the low abundance mouse int-2 transcript. ${ }^{17}$

Another approach for the analysis of DNA outside the boundaries of known sequence is inverted PCR. ${ }^{18}$ Here a pair of primers is annealed to the known sequence but orientated in such a way that they extend in opposite directions across the regions of unknown sequence. By a series of manipulations the amplified fragment so produced can then be cloned and sequenced, or sequenced directly. 
Disadvantages of PCR

First, PCR relies upon accurate sequence information. The second problem is contamination. The beauty of PCR is its sensitivity and its sensitivity is also its drawback. A set of useful guidelines about minimising errors owing to contamination has recently been published. ${ }^{19}$ Follow them! Thirdly, each pair of primers has its own set of annealing and extension criteria dependent upon temperature, cycle length, primer concentration, $\mathrm{Mg}^{2+}$ concentration, amount

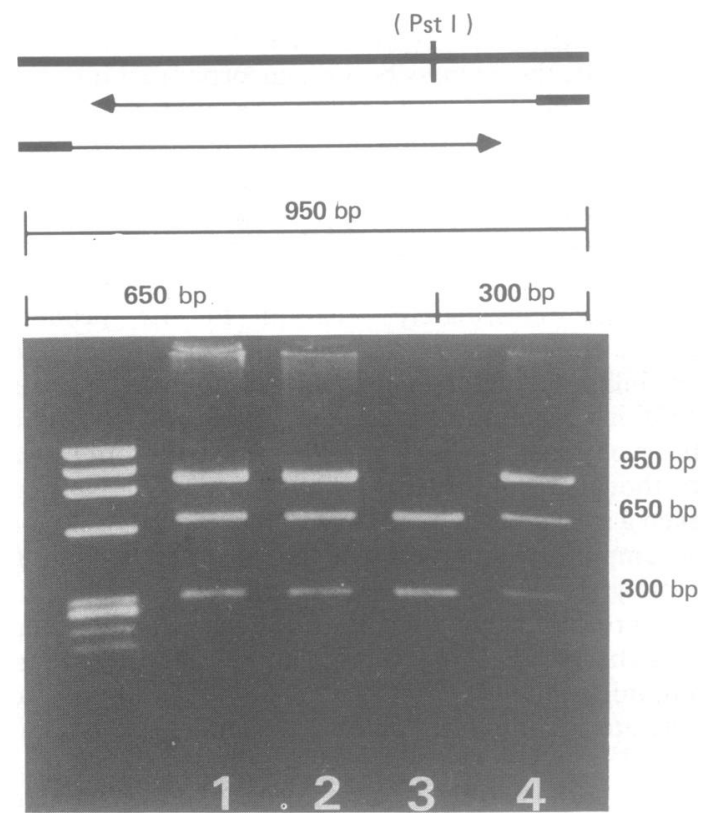

Figure 2 Prenatal diagnosis of cystic fibrosis (CF) by PCR and direct visualisation of a Pst I polymorphism after enzymatic cleavage of the amplification product. The primers, which flank a PstI polymorphism known to be in linkage disequilibrium with $C F$, were designed by Dr I McIntosh and are modified from those originally published. ${ }^{25}$ In the presence of the polymorphic PstI site, the 950 bp amplification product was cleaved to yield two smaller fragments. Lanes 1 and 2, amplified samples from the parents of a CF child, were heterozygous for the polymorphism. Lane 3, the affected child, was homozygous for the presence of the PstI polymorphism, and thus both CF genes are associated with cleavage of the site. Lane 4 is the sample from the fetus undergoing prenatal diagnosis. It has inherited only one amplified DNA fragment bearing the polymorphism associated with $C F$ and is thus a carrier for the disease. of enzyme, and amount of DNA. General guidelines are available but some manipulation of one, or all, of these criteria may be necessary to ensure accurate specific priming and consistent high quality results. There is no guaranteed recipe to optimise the reaction conditions. Lastly, a thermal cycler is not necessary for PCR but for routine service work it would become a must. The demand for thermal cyclers should ensure a competitive environment for price reductions so as to bring them into the affordable price range of most laboratories.

\section{Current applications of PCR \\ PRENATAL DIAGNOSIS}

The application of DNA techniques to prenatal diagnosis is routinely being performed at 8 to 10 weeks into pregnancy using chorionic villus material as a source of DNA. ${ }^{20}$ Prenatal diagnosis is currently based on two strategies. The first is by direct detection of the mutation, either because the mutation alters a restriction endonuclease cleavage site, detectable by Southern blotting with specific probes, ${ }^{21}$ or through the use of radioactively labelled oligonucleotides capable of specifically recognising the mutation. ${ }^{22}$ The second is by indirect detection, which is usually performed by following the inherited patterns of restriction fragment length polymorphisms through pedigrees. ${ }^{23}$ Both approaches are time consuming and both are amenable to PCR.

When a restriction enzyme site is affected, primers can be designed which flank the polymorphic site. After specific amplification, direct analysis of restriction sites is possible by incubating the amplification product with the appropriate restriction enzyme. ${ }^{24}$ The fragments produced can be electrophoresed in agarose gels and visualised directly by ethidium bromide staining and UV transillumination (fig 2). This process can be completed in a day, compared to a week by current methods (table).

Where a diagnosis involves the use of radioactively labelled oligonucleotide probes that are specific to a single mutation, a dot blot hybridisation protocol can be used with the amplified DNA, indicating either the presence or absence of the mutation. ${ }^{26}$ Again PCR gives much faster answers taking hours rather than days or weeks. This is of particular importance in prenatal diagnosis where PCR enables couples to receive an answer on the same day, rather than a

Time scale for prenatal diagnosis using DNA analysis.

\begin{tabular}{llll}
\hline \multicolumn{2}{c}{ Conventional methods of DNA analysis } & \multicolumn{2}{c}{ DNA arfalysis using PCR } \\
\hline DNA extraction & 1 day & DNA extraction & 1 day \\
Southern blot analysis & 5 days & PCR reaction & 3 hours \\
Oligonucleotide hybridisation & 4 days & Analysis: RE digestion & 1 day \\
Autoradiography & 1-7 days & Dot blot & 1 day \\
Total time required & $7-10$ days & Total time required & 3 day \\
\hline
\end{tabular}


harrowing week long wait usual with diagnosis techniques based on Southern blotting and radioactively labelled probes.

One serious problem currently worrying workers is the possibility of contamination of fetal material with maternal cells. ${ }^{27}$ One solution may be the concomitant use of primers to hypervariable regions, for example, the 5'HVR upstream of the $\alpha$ globin gene could be used to amplify fetal DNA samples. The presence of an extra band would indicate maternal contamination. Another method would be micromanipulation of the chorionic villus sample to ensure that only one or a few cells known definitively to originate from the fetus are used for PCR.

\section{PCR IN THE FORENSIC LABORATORY}

DNA fingerprinting, ${ }^{28}$ which uses the considerable allelic variation caused by differences in the number of repeat regions in vertebrate minisatellite DNA, has many applications, In forensic science it has been used to identify or exclude suspects by analysis of blood, semen, or other biological material left at the scene of the crime. ${ }^{29}$ Until recently this technology was limited because it usually required between $50 \mathrm{ng}$ and $1 \mu \mathrm{g}$ of undegraded DNA. It has now been shown that hypervariable regions can be amplified by PCR using primers on either side of the minisatellite. ${ }^{30} 31$ Alleles of between 5 and $10 \mathrm{~kb}$ have been produced and coamplification of six minisatellite loci permits the construction of a fingerprint. ${ }^{30}$ This technique is now so sensitive that only a single cell is necessary to achieve results, thus overcoming the limitation of sample size. This means that instead of venous puncture to obtain a sample suspects need only be subjected to a fingerprick or a mouthwash in order to obtain sufficient material for a test.

\section{Future applications of PCR}

PREIMPLANTATION DIAGNOSIS

The termination of pregnancies at eight weeks remains ethically unaccceptable for some couples, while those at risk for a genetically inherited disease must suffer the trauma of undergoing the first two months of a pregnancy in fear of the outcome of a prenatal diagnosis. In these cases, preimplantation diagnosis may be an acceptable alternative. This diagnosis would be made on a pre-embryo at a time between fertilisation and implantation. The application of the PCR reaction in determining the 'DNA status' of single diploid cells would therefore represent the way forward. ${ }^{1}$ In the case of such a diagnosis, a biopsy of the pre-embryo would need to be taken and for complete genetic analysis there are two stages in development when this might be done. ${ }^{32} 33$

For couples undergoing in vitro fertilisation, removal of one or two cells of the pre-embryo at the 8 to 16 cell stage, before implantation, is possible. Researchers in London recently reported the sexing of human preimplantation embryos using DNA from two cells removed at the 6 to 10 cell stage. This was done by PCR amplification followed by hybridisation of the product to $\mathrm{Y}$ chromosome specific probes. ${ }^{34}$ The pre-embryos were then permitted to develop to the blastocyst stage before being cytologically examined to confirm their sex. It is known that animal pre-embryos biopsied in such a way do develop normally.$^{35}$ Human embryos, stored in liquid nitrogen at this stage, do develop normally even when some of the cells have been damaged by freezing.

The second stage in development when a biopsy could be taken is the blastocyst stage, about six days after fertilisation. In this case fertilisation can be either in vitro or in vivo. In the latter case, blastocysts are removed from the uterus by lavage and examined. Here, cells from the trophectoderm, the future placenta, could be sampled. Biopsied blastocysts from marmoset monkeys develop normally and human blastocysts, frozen at this stage, develop normally when reimplanted. ${ }^{35}$

Preimplantation diagnosis by PCR at whatever stage in development now appears to be a viable option to couples known to be at risk for inherited genetic disorders. However, there is still much research and ethical debate to be done into in vitro fertilisation and other assisted forms of reproduction before the use of PCR in this context becomes routine.

\section{PCR AND VIROLOGY}

Two excellent reviews have recently been written about using PCR for detecting viruses, in particular HIV-1 and 2 and HTLV-1 and 2. ${ }^{76}$ The ability to recognise viruses such as these, which are difficult to culture and which might prevent the production of specific antibodies useful for conventional tests, is going to become increasingly important. ${ }^{37}$ It has been shown that HIV-1 is detected by PCR six months before seroconversion is confirmed by Western blotting. ${ }^{7}$ PCR can also be used to look for the presence of HIV in at risk cases, for example, the children of seropositive mothers or those having had intimate contact with a seropositive person. ${ }^{36}$ PCR can offer an even higher degree of sensitivity, as it can recognise whether an infection is latent or whether active transcription of the virus is occurring by using viral mRNA rather than DNA as the starting material. ${ }^{38}$ This has several important uses. It can help monitor the efficacy of antiviral drugs as well as gaining knowledge of the changes in the virus through the course of the disease.

Within the last year workers have gathered together to rationalise and standardise testing for, primarily, HIV-1 (J P Clewley, personal communication). 
Several points need clarification before PCR can be used as a routine diagnostic for HIV-1, but it is only a matter of time before this technique is commonplace in virology laboratories.

HIV-1 is not the only virus that is likely to be detected routinely by PCR. HTLV-1 and 2 as well as HIV-2 were mentioned earlier. Other possible candidates are cytomegalovirus (CMV) and herpes simplex virus (HSV). ${ }^{39}$ These are latent viruses that are usually mild or innocuous. Occasionally complications can arise, for example, if a patient is immunosuppressed or if a woman contracts CMV when pregnant. Therefore, screening for the presence of viruses such as these would be useful. Another obvious application for PCR would be the screening of donated organs or blood samples. Screening blood samples for a number of viruses could be performed in one reaction, by using appropriate manipulations of primers and PCR conditions, rather than having to perform a large variety of individual tests, thus saving time and money in such services. Human papilloma virus has been implicated in cervical cancer, but until the aetiology of this virus is better known the use of PCR as a screening tool remains premature. ${ }^{40}$ Of course, as with all PCR tests, care must be taken to avoid contamination and false negative and positive results must be controlled for.

\section{PCR AND ITS USES IN BACTERIOLOGY}

PCR is unlikely to affect significantly hospital bacteriology departments that already use reliable, well established methods to detect and characterise many micro-organisms. However, there are important situations where the use of PCR could aid bacteriology. One area concerns the detection of microbes that are expensive or difficult to culture. Another possible use of PCR is that of identifying virulence factors or antibiotic resistance mechanisms. Here present techniques are intricate and cumbersome. ${ }^{41}$

A number of DNA probes are already available that are capable of fulfilling the detection and identification roles listed above for PCR and their use has been comprehensively reviewed. ${ }^{42}{ }^{43}$ Most of these probes are used in the conventional ways, that is, they are radioactively labelled and used on dot blots of DNA from lysed micro-organisms, but there might still be room for improvement despite their increased sensitivity, specificity, and speed over traditional bacteriological techniques.

The use of PCR has obvious implications for increased sensitivity of DNA detection systems. PCR permits the use of specific, non-radioactive probes to detect single copy sequences. Reports previously attempting the use of non-radioactive detection systems used highly repetitive DNA sequences, for example, rDNA genes, or multiple copies of plasmids present within microbes, to increase the number of copies of sequence necessary for the use of these probes. ${ }^{41}$

The detection of the cloned heat labile toxin (LT) gene of toxigenic $E$ coli by means of PCR has been described. ${ }^{44}$ It was shown that after 24 cycles of amplification, $1 \mathrm{fg}$ of cloned LT gene could be detected using a biotin labelled probe, representing a $10^{3}$ fold increase of sensitivity over unamplified material and without the use of radioactivity.

Most DNA probes which are currently used to detect microbes are large. Some organisms, for example Neisseria gonorrhoeae, contain plasmids, autonomous pieces of DNA that are easily isolated and that can be used as highly specific probes. ${ }^{41}$ However, most DNA probes isolated from micro-organisms contain sequences which are not species specific and therefore cross hybridise to give dubious results. In order to enhance their specificity, unique DNA sequences are identified in these probes. Amplifying these smaller fragments, or just parts of them, by PCR and using biotinylated oligonucleotide probes, or direct sequencing, could aid the specific identification of microbes and simultaneously save time and expense compared with the use of radioactivity.

There still remain some situations where PCR cannot be used. Doubts as to its efficacy in the analysis of complex samples such as faecal material have been raised. ${ }^{45}$ Also, the detection of an organism has to be interpreted carefully. While the presence of Mycobacterium tuberculosis in cerebrospinal fluid would be diagnostic, what does the presence of Salmonella enteriditis in chickens or Legionella in water tanks mean? These organisms, along with many other pathogens, are probably widespread but present at very low levels. Bearing this in mind, great care with contamination must also be taken.

\section{PCR AND CANCER THERAPY}

The most likely reason for relapse in cancer therapy is that not all the cancer cells are destroyed by the treatment, allowing residual tumour cells to become re-established. PCR has been used to detect residual cells containing the translocation $t(14 ; 18)(\mathrm{q} 32 ; \mathrm{q} 21)$, present in $90 \%$ of follicular lymphomas, from patients in whom conventional techniques had indicated eradication of the disease, and thus alerted the clinician to the need for further therapy. ${ }^{46}$ PCR has been used to characterise and detect other oncogenic mutations, for example that occurring in the c-Ki-ras gene before the development of malignancy. ${ }^{478}$ Research of this type, using the sensitivity of PCR, might enable the development of preventive measures against cancer. One possible way of doing this is by the design and construction of specific antibodies against cancer cells. ${ }^{49}$ PCR is helping in this aspect of research too, as workers are currently using PCR to engineer antibodies. ${ }^{50}$ 


\section{Conclusions}

From the information presented here, it can be seen that PCR offers a wealth of possibilities to many fields of medicine. The progress made over the last three years has been phenomenal and has resulted in the development of an extremely sensitive and versatile laboratory technique. One cannot help but wonder what the future holds.

We would like to thank Drs D Love and W O C Cookson for reading the article and Jennifer Bloomfield, Jenny Hall, and Jennifer Love for helpful discussions. Thanks also to Liz Rose, Linda Roberts, and Irene Fulton for their patient typing of this manuscript.

1 Li H, Gyllensten UB, Cui X, Saiki R, Erlich HA, Arnheim N. Amplification and analysis of DNA sequences in single human sperm and diploid cells. Nature 1988;335:414-7.

2 Bunn HF, Forget BG. Hemoglobin: molecular, genetic and clinical aspects. Philadelphia: Saunders, 1986.

3 Collins FS, Weissman SM. The molecular genetics of human hemoglobin. In: Lohn WE, Moldave K, eds. Progress in nucleic acids research and molecular biology. Vol 31. New York: Academic Press, 1984:315-437.

4 Saiki RK, Scharf S, Faloona F, et al. Enzymatic amplification of $\beta$-globin genomic sequences and restriction site analysis for diagnosis of sickle cell anaemia. Science 1985;230:1350-4.

5 Mullis KB, Faloona FA. Specific synthesis of DNA in vitro via a polymerase catalysed chain reaction. Methods Enzymol 1987; 155:335-50.

6 White TJ, Arnheim N, Erlich HA. The polymerase chain reaction. Trends Genet 1989;5:185-9.

7 Schochetman G, Ou C-Y, Jones WK. Polymerase chain reaction. F Infect Dis 1988;158:1154-7.

8 Marx JL. Multiplying genes by leaps and bounds. Science 1988;240:1408-10.

9 Bell J. The polymerase chain reaction. Immunol Today 1989;10 $351-4$.

10 Saiki RK, Gelfand DH, Stoffel S, et al. Primer-directed enzymatic amplification of DNA with a thermostable DNA polymerase. Science 1988;239:487-91.

11 Erlich HA, Gelfand DH, Saiki RK. Specific DNA amplification. Nature 1988;331:461-2.

12 Scharf SJ, Horn GT, Erlich HA. Direct cloning and sequence analysis of enzymatically amplified genomic sequences. Science 1986;233:1076-8.

13 Winship PR. An improved method for directly sequencing PCR amplified material using dimethyl sulphoxide. Nucleic Acids Res 1989;17:1266.

14 Gyllensten UB, Erlich HA. Generation of single-stranded DNA by the polymerase chain reaction and its application to direct sequencing of the HLA-DQA locus. Proc Natl Acad Sci USA 1988;85:7652-6.

15 Berchtold MW. A simple method for direct cloning and sequencing cDNA by the use of a single specific oligonucleotide and oligo (dT) in a polymerase chain reaction (PCR). Nucleic Acids Res 1989;17:453.

16 Loh EY, Elliott JF, Cwirla S, Lanier LL, Davis MM. Polymerase chain reaction with single sided specificity: analysis of $T$-cell receptor $\delta$ chain. Science 1989;243:217-20.

17 Frohman MA, Dush MK, Martin GR. Rapid production of fulllength cDNAs from rare transcripts: amplification using a single gene-specific oligonucleotide primer. Proc Natl Acad Sci USA 1988;85:8998-9002.

18 Triglia T, Peterson MG, Kemp DJ. A procedure for in vitro amplification of DNA segments that lie outside the boundaries of known sequences. Nucleic Acids Res 1988;16:8186.

19 Kwok S, Higuchi R. Avoiding false positives with PCR. Nature 1989;339:237-8.

20 Old JM, Weatherall DJ, Ward RHT, et al. First trimester diagnosis of the haemoglobin disorders. Ann NY Acad Sci 1985;445:349-56.

21 Thein SL, Lynch JR, Old JM, Weatherall DJ. Direct detection of Hb E with MnlI. F Med Genet 1987;24:110-1.
22 Thein SL, Lynch JR, Weatherall DJ, Wallace RB. Direct detection of $\mathrm{Hb} \mathrm{E}$ with a synthetic oligonucleotide-application to prenatal diagnosis. Lancet 1986;i:93.

23 Brock DJH. Prenatal diagnosis of cystic fibrosis. Arch Dis Child 1988;63:701-4.

24 Kogan SC, Doherty M, Gitschier J. An improved method for prenatal diagnosis of genetic diseases by analysis of amplified DNA sequences. $N$ Engl f Med 1987;317:985-90.

25 Feldman GL, Williamson R, Beaudet AL, O'Brien WE. Prenatal diagnosis of cystic fibrosis by DNA amplification for detection of KM-19 polymorphism. Lancet 1988 ;ii: 102

26 Saiki RK, Bugawan TL, Horn GT, Mullis KB, Erlich HA. Analysis of enzymatically amplified $\beta$-globin and HLA-DQ $\alpha$ DNA with allele-specific oligonucleotide probes. Nature 1986; 324:163-6.

27 Chamberlain JS, Gibbs RA, Ranier JE, Nguyen PN, Caskey CT. Deletion screening of the Duchenne muscular dystrophy locus via multiplex DNA amplification. Nucleic Acids Res 1988;16: 11141-71.

28 Jeffreys AJ, Wilson V, Thein SL. Hypervariable 'minisatellite' regions in human DNA. Nature 1985;314:67-73.

29 Fawcett AS, ed. Dead men tell tales: 7 Forensic Sci Soc 1988;28:5-6.

30 Jeffreys AJ, Wilson V, Neumann R, Keyte J. Amplification of human minisatellites by the polymerase chain reaction: towards DNA fingerprinting of single cells. Nucleic Acids Res 1988;16: 10953-71.

31 Higuchi $\mathrm{R}$, von Beroldingen $\mathrm{CH}$, Sensabaugh GF, Erlich HA. DNA typing from single hairs. Nature 1988;332:543-6.

32 Penketh R, McLaren A. Prospects for prenatal diagnosis during preimplantation human development. In: Bailliere's clinical obstetrics and gynaecology. Fetal diagnosis of genetic defects. Eastbourne: Saunders, 1987:747-64.

33 McLaren A. The IVF conceptus. Research today and tomorrow: in in vitro fertilisation and other assisted reproduction. Ann NY Acad Sci 1988;541:639-45.

34 Handyside AH, Penketh RJA, Winston RML, et al. Biopsy of human preimplantation embryos and sexing by DNA amplification. Lancet 1989;i:347-9.

35 McLaren A. Can we diagnose genetic disease in pre-embryos? New Scientist 1987;10 December:42-7.

36 Clewley JP. The polymerase chain reaction, a review of the practical limitations for human immunodeficiency virus diagnosis. $\mathcal{F}$ Virol Methods 1989;25:179-88.

37 Ou CY, Kwok S, Mitchell S, et al. DNA amplified for direct detection of HIV-1 in DNA of peripheral blood mononuclear cells. Science 1988;239:295-7.

38 Byrne BC, Li JJ, Sninsky J, Polesz BJ. Detection of HIV-1 RNA sequences by in vitro DNA amplification. Nucleic Acids Res 1988;16:4165

39 Maitland N. Report from 1st National Symposium on the Polymerase Chain Reaction, 9 May 1989, London.

40 Young LS, Bevan IS, Johnson MA, et al. The polymerase chain reaction: a new epidemiological tool for investigating cervical human papillomavirus infection. $\mathrm{Br}$ Med $\mathcal{f}$ 1989;298:14-8.

41 Zwadyk P, Cooksey PC. Nucleic acid probes in microbiology. CRC Crit Rev Clin Lab Sci 1987;25:71-103.

42 Eisenstein BI, Engleberg NC. Applied molecular genetics: new tools for microbiologists and clinicians. F Infect Dis 1986;153: 416-30.

43 Matthews JA, Kricka LJ. Analytical strategies for the use of DNA probes. Anal Biochem 1988;169:1-25.

44 Olive DM, Atta AI, Setti SV. Detection of toxigenic Escherichia coli using biotin labelled DNA probes following enzymatic amplification of the heat labile toxin gene. Mol Cell Probes 1988;2:47-57.

45 Bains W. Disease, DNA and diagnosis. New Scientist 1989;6 May:48-51.

46 Lee MS, Chang KS, Cabanillas F, Freireich EJ, Trujillo JM, Stass SA. Detection of minimal residual cells carrying the $\mathrm{t}(14 ; 18)$ by DNA sequence amplification. Science 1987;237: 175-8.

47 McMahon G, Davis E, Wogan GN. Characterisation of c-Ki-ras oncogene alleles by direct sequencing of enzymatically amplified DNA from carcinogen-induced tumours. Proc Natl Acad Sci USA 1987;84:4974-8.

48 Bos JL, Fearon ER, Hamilton SR, et al. Prevalence of ras gene mutations in human colorectal cancers. Nature 1987;327:293-7.

49 Reichmann L, Clark M, Waldmann H, Winter G. Reshaping human antibodies for therapy. Nature 1988;332:323-7.

50 Winter G. Report from Ist National Symposium on the Polymerase Chain Reaction, 9 May 1989, London. 